\title{
Surgical correction of nasal valve collapse
}

\author{
Joo Yeon Kim, MD, PhD®i , Gi Yoon Nam, MD®i , Jae Hwan Kwon, MD, PhD i \\ Department of Otolaryngology-Head and Neck Surgery, Kosin University College of Medicine, Busan, Rep. of Korea
}

\begin{abstract}
Background: Nasal obstruction due to internal and/or external nasal valve collapse can be occurred sometimes. To overcome internal nasal valve obstruction, spreader grafts, butterfly grafts, flaring sutures and suspension sutures have been described to be effective. The correction of the external valve collapse can be done by alar batten, alar rim graft, and various other methods.

Objective: We report successful results for the patients with severe nasal valve collapse during respiration using appropriate surgical techniques for individual causes.

Methods: We undertook a retrospective study of 8 patients diagnosed with nasal valve collapse. Each patient underwent one or multiple procedures according to individual problems regard to their nasal obstruction. The visual analogue scale (VAS) and Nasal Obstruction Symptom Evaluation (NOSE) validated survey was used to measure a patient's subjective postoperative change in nasal obstruction. Facial photography and video for estimating alar collapse were taken to compare the change of pre- and postoperative nasal breathing and shape.

Results: Four out of eight patients had a static collapse of the nasal valves, while the other four had a dynamic collapse. The remaining six patients had no previous nasal trauma or surgical history. Each patient underwent surgeries such as alar batten graft, alar rim graft, and debulking operation according to their respective deformities. The endonasal and open approaches were used in five and three patients, respectively. After surgery, patient satisfaction (VAS) improved from 6.6 to 2.5 points, and the NOSE scale scores improved from 15.1 to 7.1 points.

Conclusion: Nasal obstruction due to nasal valve collapse can be effectively treated with various surgical techniques. After a thorough examination and analysis, the underlying cause of the nasal obstruction should be analyzed, and one or multiple procedures should be chosen according to each individual problem to get good results.
\end{abstract}

Keywords: nasal valve collapse; nasal valve surgery; rhinoplasty

\section{Introduction}

The nasal valve is a functionally and cosmetically important anatomical part that is largely divided into internal and external nasal valves. Generally, the internal nasal valve comprises of the nasal septum, caudal end of the upper lateral cartilage, and piriform aperture, while the external nasal valve comprises the alar rim, nasal sill, and columella [1].

Nasal valve collapse can be classified into dynamic and static collapses according to their pathophysiological origin. Dynamic collapse involves negative pressure during inspiration, causing the collapse of weakened nasal valve structures and subsequent nasal occlusion. Conversely, static collapse is characterized by stenosis of the external nostril or nasal cavity, septal deviation, and/or hypertrophy of the inferior nasal concha due to congenital, or anthropogenic causes, infections, and/or trauma, leading to a reduced cross-sectional area of the nostril.

Nasal valve collapse may also be divided into internal and

Received November 10, 2021; Revised November 29, 2021; Accepted December 9, 2021

Corresponding author: Jae Hwan Kwon

E-mail: entkwon@hanmail.net

This is an Open Access article distributed under the terms of the Creative Commons Attribution Non-Commercial License (http://creativecommons.org/licenses/by-nc/4.0), which permits unrestricted non-commercial use, distribution, and reproduction in any medium, provided the original work is properly cited.

Copyright $@ 2021$ Korean Society of Korean Cosmetic Surgery and Medicine (KSKCS \& KCCS). 
external nasal valves that collapse according to the anatomical location. Internal nasal valve collapse is generally observed in elderly patients with weak nasal structural support or in individuals with a history of rhinoplasty. External nasal valve collapse is relatively rare compared to internal nasal valve collapse, and is commonly observed in patients with narrow nostrils, protruding nose tips, and/or weak and thin lateral nasal walls [2-4].

Toriumi et al. [5] introduced the following methods in 1997 to strengthen the structure of the valve area: spreader graft [6], butterfly graft [7], suspension suture technique [8], and alar batten graft. Nasal valve collapse caused by a previous surgery or injury can be treated via Z-plasty [9] or a conchal composite graft to expand the nasal space by providing structural support. Herein, we report eight cases of nasal stuffiness due to nasal valve collapse who underwent appropriate treatment and exhibited improvement in symptoms.

\section{Materials and methods}

\section{Participants}

Patients who were diagnosed with lateral and medial nasal valve collapse accompanied by severe nasal occlusion and those who underwent surgery at the Kosin University Gospel Hospital between October 2010 and April 2017 were included. Medical records were retrospectively analyzed. Patients who showed symptoms of nasal occlusion caused by caudal septal deviation without nasal polyps or rhinosinusitis were excluded. Finally, eight participants were included in our study. Each patient was given an opportunity to review the manuscript and consented to its publication.

\section{Methods}

Subjective evaluation of nasal congestion was conducted using the visual analogue scale (VAS) and nasal obstruction symptom evaluation (NOSE) scale pre- (baseline) and post-operation (4 to 6 weeks after surgery). Additionally, pre- and postoperative facial photographs were compared to assess changes in the appearance of the nose. Nasal appearance during expiration and maximum inspiration was also recorded as a video to evaluate alar stenosis and surgical correction before and after surgery.

The operation was conducted on patients who met the inclusion criteria as aforementioned. To determine the cause of the nasal occlusion, a cotton swab was used during inspiration to support the external and internal nasal valves and to expand the space by pushing the curved nasal septum subsequent improvement in nasal stuffiness was then assessed to identify the epicenter of the cause. Appropriate surgical methods were selected accordingly [10]. Surgery, such as alar batten, rim graft, and debulking, was debulking, was performed according to the deformity found in each patient.

\section{Results}

Two female and six male with a mean age of 43 years (21-59 years) were included in this study. One patient had a history of rhinoplasty due to traumatic injury. Five patients had a bilateral stenosis, while three patients showed a unilateral alar stenosis. Three patients underwent open approach surgeries, and five patients underwent endonasal surgery. There were 4 cases each of static collapse and of dynamic collapse (Table 1).

Patients with dynamic collapse showed collapse of the internal and external nasal valves during inspiration. Some patients had unilateral collapse, while others had bilateral collapse with a more prominent unilateral collapse. The alar batten graft was conducted at the epicenter of the collapse, and an alar rim graft was performed to strengthen the external nasal valve. In patients who had dynamic collapse accompanied by a twisted nose, osteotomy was conducted in addition to the alar batten graft and alar rim graft, in order to widen the narrowed inner valve space. Case 4 showed collapse of the internal nasal valve on the right side and a collapse of the external nasal valve on the left side. Thus, an oval-shaped alar batten graft was placed between the upper and lower lateral nasal cartilages on the right side, and a band-shaped alar batten graft was placed on the lateral side of the lower lateral nasal cartilage on the left side. Among the patients with static collapse, three showed narrowing of the nostrils due to contracture deformation of the alar rim tissues from trauma and burns, and one showed narrowing of the nostril from congenital bilateral thickening of the soft tissues of the alar rim and columella. Surgery was performed

Table 1. Baseline patients' characteristics

\begin{tabular}{cccccc}
\hline No. & Age (yr) & Sex & Previous operation & Type & Direction \\
\hline 1 & 40 & Male & $\mathrm{X}$ & Dynamic & Right \\
2 & 52 & Male & $\mathrm{X}$ & Dynamic & Both \\
3 & 59 & Male & $\mathrm{X}$ & Dynamic & Both \\
4 & 35 & Male & $\mathrm{X}$ & Dynamic & Both \\
\hline 5 & 36 & Male & $\mathrm{X}$ & Static & Left \\
6 & 21 & Male & $\mathrm{X}$ & Static & Both \\
7 & 48 & Female & $\mathrm{O}$ & Static & Left \\
8 & 53 & Female & $\mathrm{X}$ & Static & Both \\
\hline
\end{tabular}


to widen the nostrils narrowed by the scars. The thickened soft tissue was excised to an adequate shape, and the weakened structure was strengthened using an alar rim graft. The narrowed area was widened by removing the scar through Z-plasty (Table 2). The mean preoperative VAS and NOSE scale scores in our subjects were 6.6 and 15.1 points, respectively. The mean postoperative scores were 2.5 points for VAS and 7.1 points for NOSE scale, suggesting an improvement in symptoms (Fig. 1). In the comparison of pre- and postoperative images, the crosssectional area of the nostril became wider post-surgery; furthermore, nasal valve collapse during inspiration was corrected.

Table 2. Patient-specific surgical correction for anatomical causes

\begin{tabular}{|c|c|c|c|}
\hline No. & Anatomical deformity & $\begin{array}{l}\text { Surgical } \\
\text { approach }\end{array}$ & Surgical technique \\
\hline 1 & $\begin{array}{l}\text { Collapse of internal and } \\
\text { external nasal valve }\end{array}$ & Closed & Alar batten and rim graft \\
\hline 2 & $\begin{array}{l}\text { Collapse of internal and } \\
\text { external nasal valve } \\
\text { Depressed nose }\end{array}$ & Open & $\begin{array}{l}\text { Alar batten and rim graft } \\
\text { Dorsal augmentation } \\
\text { Shield and cap graft } \\
\text { Spreader graft }\end{array}$ \\
\hline 3 & $\begin{array}{l}\text { Collapse of internal and } \\
\text { external nasal valve } \\
\text { Twisted nose }\end{array}$ & Open & $\begin{array}{l}\text { Alar batten and rim graft } \\
\text { Medial and lateral } \\
\text { osteotomy }\end{array}$ \\
\hline 4 & $\begin{array}{l}\text { Collapse right internal } \\
\text { nasal valve } \\
\text { Collapse left external } \\
\text { nasal valve }\end{array}$ & Closed & $\begin{array}{l}\text { Alar batten graft, right } \\
\text { Alar rim graft, left }\end{array}$ \\
\hline 5 & $\begin{array}{l}\text { Cicatrical stenosis of alar } \\
\text { rim }\end{array}$ & Closed & $\begin{array}{l}\text { Scar revision } \\
\text { (wedge resection) } \\
\text { Alar rim graft } \\
\text { Debulking of alar }\end{array}$ \\
\hline 6 & $\begin{array}{l}\text { Thick alar rim } \\
\text { Thick columella }\end{array}$ & Closed & $\begin{array}{l}\text { Debulking of alar rim } \\
\text { and columella }\end{array}$ \\
\hline 7 & $\begin{array}{l}\text { Cicatrical stenosis of alar } \\
\text { lobule }\end{array}$ & Closed & $\begin{array}{l}\text { Scar revision } \\
\quad \text { (double Z plasty) } \\
\text { Alar rim graft } \\
\text { Dorsal augmentation } \\
\text { Cap graft }\end{array}$ \\
\hline 8 & $\begin{array}{l}\text { Cicatrical stenosis of alar } \\
\text { lobule }\end{array}$ & Open & $\begin{array}{l}\text { Alar rim graft } \\
\text { Dorsal augmentation } \\
\text { Cap graft }\end{array}$ \\
\hline
\end{tabular}

\section{Case 1. (no. 1)}

A 40-year-old who experienced nasal congestion during deep breathing was admitted to Kosin University Gospel Hospital. He had no history of nasal surgery, and physical examination showed that the right alar was in close proximity to the columella during inspiration, which led to difficulty in inspiration. Nasal stenosis due to dynamic collapse of the lateral wall, including the internal and naval valves, was diagnosed. He subsequently underwent surgery using an closed approach under general anesthesia. The nasal septal cartilage was used for an alar batten graft and alar rim graft at the site with the most severe collapse in the right nasal lateral wall. Nasal stuffiness was improved one month postoperatively VAS score decreased from 7 points preoperatively to 2 points post-surgery, and the NOSE scale score decreased from 16 points preoperatively to 7 points post-surgery. Post-surgical images in Fig. 2 show that the lateral nostril was widened with a wider alar and no collapse of the alar was noted during inspiration.

\section{Case 2. (no. 3)}

A 59-year-old male complaint of bilateral nasal congestion and a twisted nose due to previous facial trauma. Physical examination showed that the alar and columella were in close proximity to each other during inspiration, reducing the nasal space. Nasal stuffiness due to a deviated nasal septum and dynamic collapse of the nasal valve was diagnosed, and an open rhinoplasty approach was performed. A spreader graft was used to correct the curved nasal septum. An alar batten and alar rim graft were conducted at the site with the most severe collapse in the lateral wall on both sides. VAS score decreased from 8 points preoperatively to 2 points postoperatively, while the NOSE scale score reduced from 17 points to 9 points one month postoperatively, indicating an improvement in nasal stuffiness. Postoperative image findings also showed correction of the twisted nose and collapse of the alar during inspiration (Fig. 3).
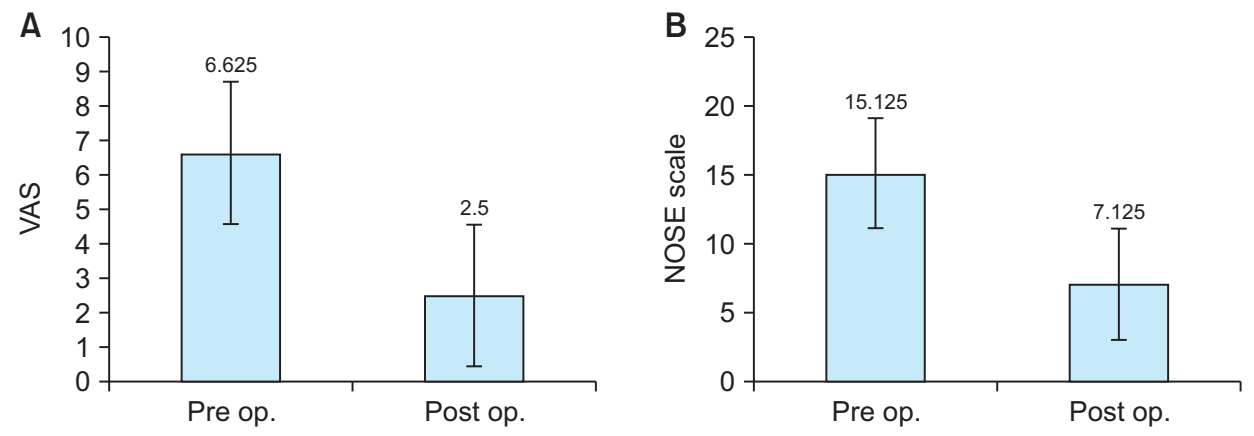

Fig. 1. (A) Change of pre- and postoperative VAS. (B) Change of pre- and post-operative NOSE scale. VAS, visual analogue scale; NOSE, nasal obstruction symptom evaluation. 

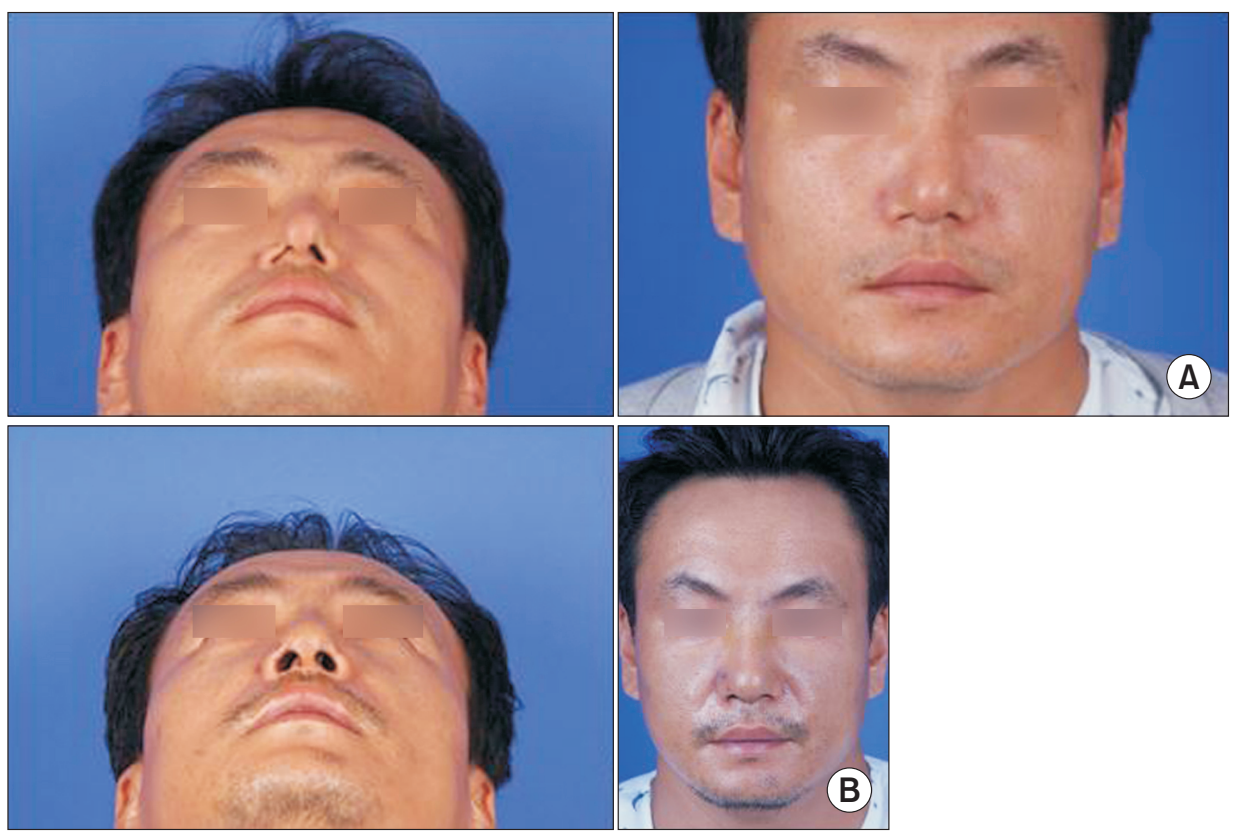

Fig. 2. Case no.1: facial photos during inspiration demonstrate collapse of the right nasal nostril, preoperatively (A). Photographs taken 1 month after surgery show that the lateral nasal wall including alar does not collapse with inspiration (B).

\section{Case 3. (no. 7)}

A 36-year-old male complaint of nasal congestion on the left side due to complete stenosis of the left nostril from facial burn two years ago. The alar rim was asymmetrical; nostril stenosis due to soft tissue adhesion on the lateral part of the left alar rim was noted. The patient was diagnosed with nasal congestion due to static collapse of the nasal valve, and endonasal surgery was performed. Z-plasty was performed on the left alar rim to widen the nostril, and the soft tissue was partially excised. The right auricular cartilage was harvested, and an alar rim graft was placed on the left side. One year after the first surgery, an endonasal approach for a soft tissue debulking operation was performed using and V-shaped incision of the left alar rim. The left auricular cartilage was harvested, and an alar rim graft was conducted more externally than the previous alar rim graft. A nostril retainer was then placed for six months to prevent restenosis. The postoperative image findings in Fig. 4 show an enlarged left nostril and a more symmetrical alar rim compared to the preoperative images.

\section{Discussion}

The nasal valve is the most important nasal component that determines the airflow in the nasal cavity, nasal valve collapse leads to nasal stuffiness. Unlike that of Caucasians, the angle of the internal nasal valve of Koreans is relatively wide, and the skin and soft tissue of the alar and dorsum nasi are thick. Thus, lateral wall collapse is rare. However, congenitally thin soft tis- sue, weak cartilage, and structural damage, such as excessive excision of the lower lateral cartilage during previous rhinoplasty, may lead to a collapse of the nasal valve and consequent nasal stuffiness [11,12]. A key factor for the successful surgical correction of nasal occlusion is the accurate determination of the location of the anatomical site of collapse. Therefore, clinicians must determine whether the external or internal valve collapses, and whether the problem is dynamic collapse caused by narrowing of the nostrils during inspiration, or static collapse caused by narrowing of the nasal cavity due to anatomical issues. Adequate surgical treatment must be provided accordingly [13]. A spreader graft [6] is useful for correcting middle nasal vault. The butterfly graft, which has been reported by Stucker and Hoasjoe [7], involves harvesting the auricular cartilage into the shape of butterfly wings, which is then placed on the both upper lateral cartilage; this is preferred in patients with static collapse caused by an increased supratip space. The suspension suture technique was first suggested by Paniello [8]. In this method, a non-absorbable suture is applied to the periosteum located on the middle one-third of the periosteum of the infraorbital rim and nasal mucosa, which is then pulled together superolaterally. This strengthens the lateral wall support, thereby effectively preventing collapse. In 1997, Toriumi et al. [5] reported a case of successful correction of nasal valve collapse using an alar batten graft. In this procedure, the harvested auricular cartilage or graft collected from the nasal septum was inserted into the area from the lateral crura end of the lower lateral cartilage to the outer margin of the piriform aperture. This method 

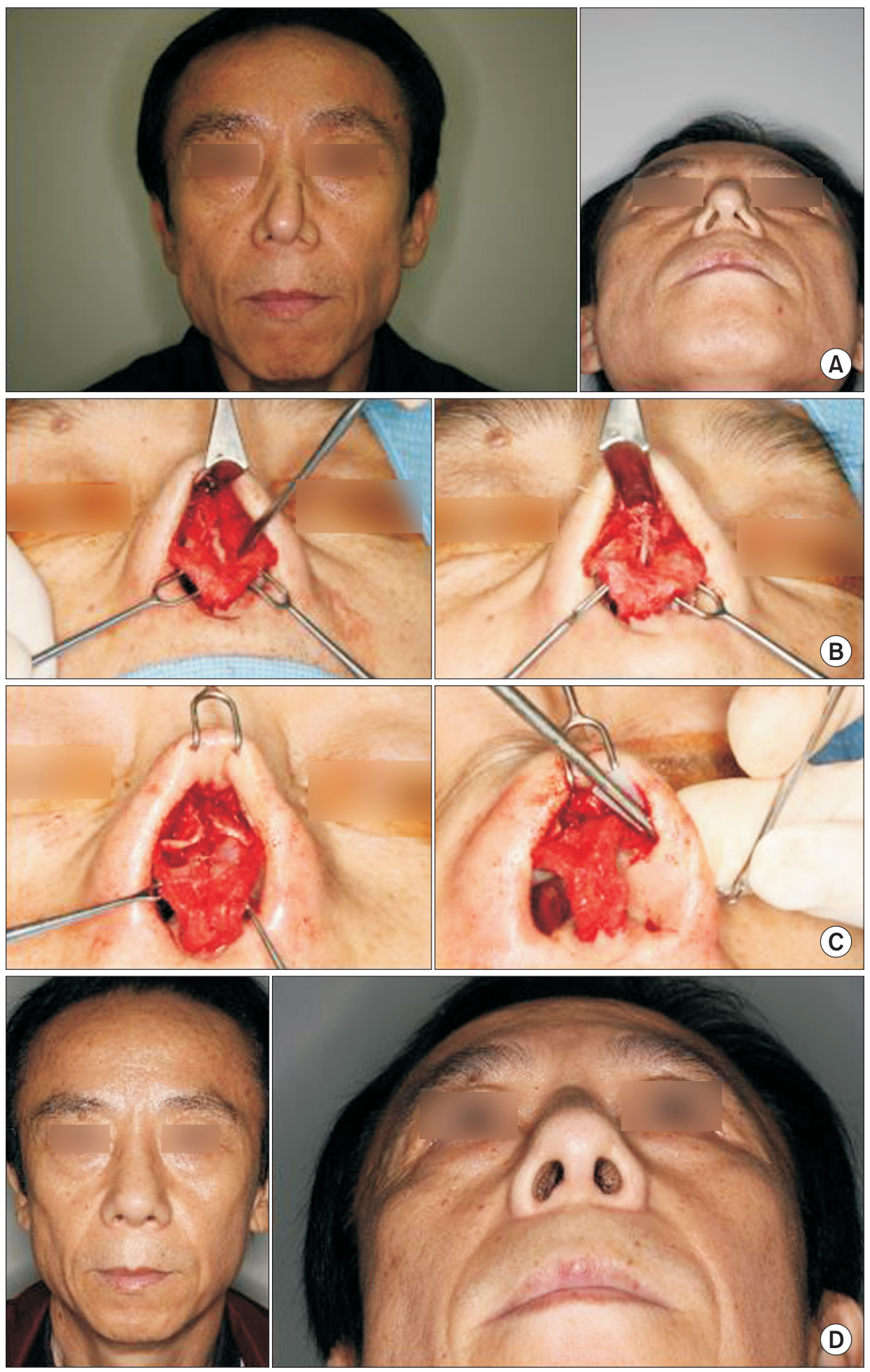

Fig. 3. Case no.3: facial photos during inspiration demonstrate the collapse of both nasal nostril and twisted nasal dorsum, preoperatively (A). Intraoperative photograph shows twisted septum with spreader graft, alar batten and rim graft (B, C). Photographs taken 6 weeks after surgery show that the improved dorsal aesthetic lines and alar base with inspiration (D). can effectively correct the collapse of the upper alar that can occur during inspiration. Congenital nasal deformation, scars from burns, structural stenosis, and defects after surgery can be treated with Z-plasty [9] to remove scars and improve stenosis of the nostrils and nasal vestibular skin. If insufficient skin or hard scars are present, the conchal composite graft can be used to expand the space with structural support. Various surgical procedures have been sought to treat nasal valve collapse; however, these procedures do not guarantee functional and structural improvement. The ideal implant for structural reinforcement of 


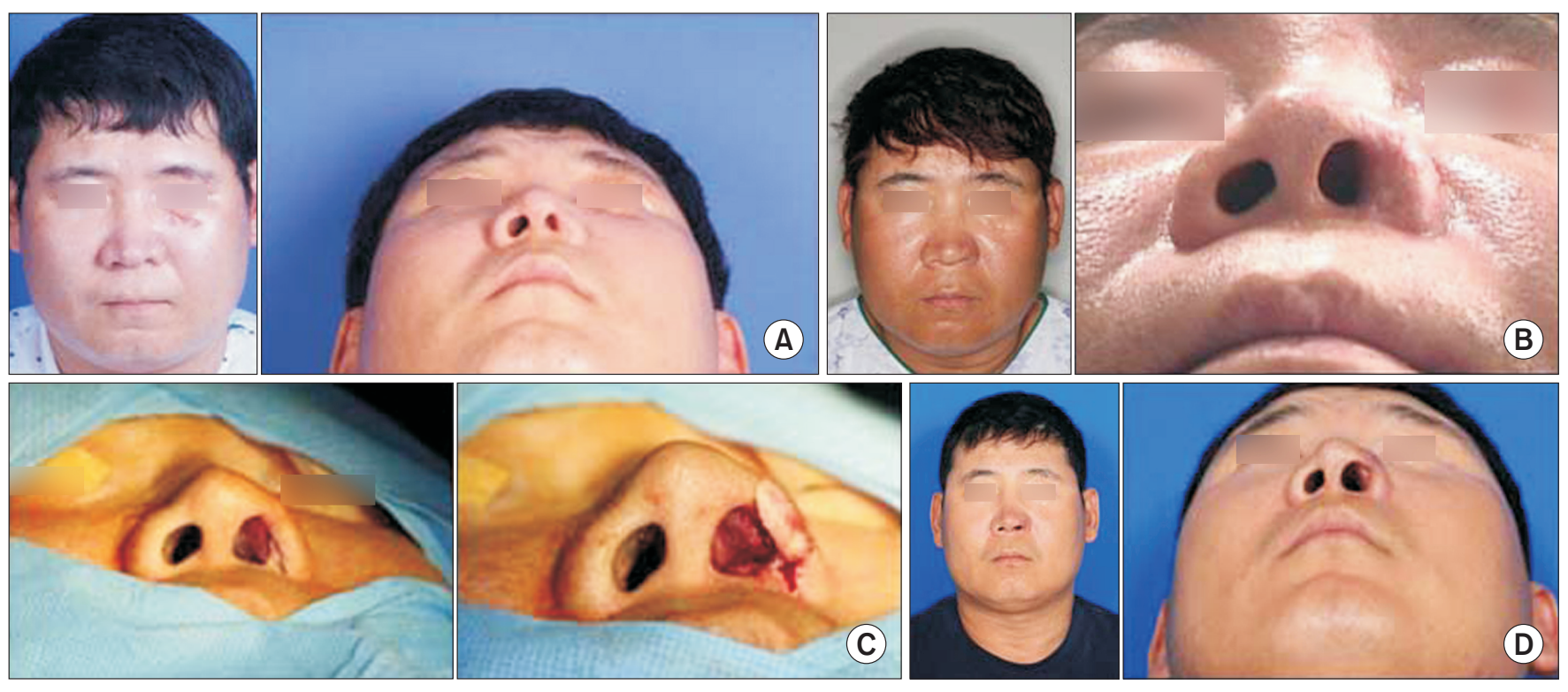

Fig. 4. Case no. 7: facial photos demonstrate complete stenosis of left nasal vestibule after facial burn (A). This patient underwent Z-plasty, debulking surgery, and alar rim graft to widen and support nasal nostril (B). One year later after 1st operation, left alar rim debulking and augmentation surgery was performed (C). Photographs taken 1 year after 2nd surgery show widen left nostril and much improved left alar rim shape compared to preoperative one (D).

the nasal valve must be unlimited in its extent of use and should not lose its shape even after a long period implantation. In addition, the implant must be biocompatible. In several studies, alloplastic materials, such as Medpore, Gord-Tex, silicon, and Supramid, have been used to correct nasal valve collapse; however, these materials may cause side effects [14]. Autologous cartilage can be obtained from the auricle, septum, and ribs. The most effective treatment method is to harvest the nasal septum and auricular cartilage, widen the diameter of the internal nasal valve, and strengthen the lateral angle of the lower lateral cartilage for structural support of the piriform aperture [15]. Sheen [6] used a spreader graft to dilate the nasal valve and increase its cross-sectional area. However, although this method can lateralize the upper and lower lateral cartilages, the nasal valve angle is not affected. Park [16] used a spreader graft with a flaring suture to lift the upper lateral cartilage and found that symptoms of nasal occlusion improved. Alar batten grafting involves cutting the cartilage graft into a curved shape, which is inserted into a pocket in the collapsed area of the largest lateral wall. Alar batten grafts can effectively correct the wide distribution of lateral angle deformations and defects and can provide precise structural support for the collapsed area of the lateral wall without additional deformation [17]. Gunter and Friedman [18] widened the lateral angle using lateral crural strut grafts in 118 patients. Toriumi $[19,20]$ reported that internal and external nasal valve collapse was corrected using an alar batten graft, and Becker and Becker [21] reported the results of alar batten grafting in 46 patients. Byrd et al. [22] functionally evaluated alar batten grafts to correct alar distortion and contracture after removal of the alar tumor. These studies suggest that the alar batten graft is effective in correcting nasal valve collapse and deformation of the lateral angle; however, there are still few alar batten graft cases have been reported in Korea. In these cases from previous studies, the alar batten graft and alar rim graft improved nasal stuffiness in patients with a dynamically collapsed nasal valve. In patients with a narrow cross-sectional area of the nostril due to stenosis from burns or congenital reasons who were diagnosed with a static collapse of nasal valves, debulking operation, alar rim graft, and placement of a nostril retainer increased the cross-sectional area of the nostril and improved nasal stuffiness. In our study, improved VAS and NOSE scale scores suggested that nasal stuffiness improved after surgery without symptom recurrence. In conclusion, there are various causes that may lead to nasal valve collapse. And effective treatments can be achieved by selecting the appropriate surgical method for each causes.

\section{Conflicts of interest}

The authors have nothing to disclose. 


\section{References}

1. Jung DH, Kim YJ, Choi WS, Han CJ, Jang TY. Treatment of the nasal valve stenosis. Korean J Otorhinolaryngol-Head Neck Surg 1999;42:727-33.

2. Fischer $H$, Gubisch W. Nasal valves--importance and surgical procedures. Facial Plast Surg 2006;22:266-80.

3. Schlosser RJ, Park SS. Functional nasal surgery. Otolaryngol Clin North Am 1999;32:37-51.

4. Friedman M, Ibrahim H, Syed Z. Nasal valve suspension: an improved, simplified technique for nasal valve collapse. Laryngoscope 2003;113:381-5.

5. Toriumi DM, Josen J, Weinberger M, Tardy ME Jr. Use of alar batten grafts for correction of nasal valve collapse. Arch Otolaryngol Head Neck Surg 1997;123:802-8.

6. Sheen JH. Spreader graft: a method of reconstructing the roof of the middle nasal vault following rhinoplasty. Plast Reconstr Surg 1984;73:230-9.

7. Stucker FJ, Hoasjoe DK. Nasal reconstruction with conchal cartilage. Correcting valve and lateral nasal collapse. Arch Otolaryngol Head Neck Surg 1994;120:653-8.

8. Paniello RC. Nasal valve suspension. An effective treatment for nasal valve collapse. Arch Otolaryngol Head Neck Surg 1996;122:1342-6.

9. Dutton JM, Neidich MJ. Intranasal Z-plasty for internal nasal valve collapse. Arch Facial Plast Surg 2008;10:164-8.

10. Chang J. Surgery for nasal valve compromise. Korean J Otorhinolaryngol-Head Neck Surg 2014;57:214-25.

11. Jin HR, Mo JH. Surgical correction of dynamic nasal valve collapse. Korean J Otorhinolaryngol-Head Neck Surg 2009;52:175-9.

12. Choi IJ, Kim KH, Kim NY, Lee MC. Diagnosis and treatment of dynamic external nasal valve collapse: application of alar batten graft and alar flaring suture. Korean J OtorhinolaryngolHead Neck Surg 2016;59:551-6.

13. Rohrich RJ, Raniere J Jr, Ha RY. The alar contour graft: correction and prevention of alar rim deformities in rhinoplasty. Plast Reconstr Surg 2002;109:2495-505; discussion 2506-8.

14. Williams JD, Romo T 3rd, Sclafani AP, Cho H. Porous highdensity polyethylene implants in auricular reconstruction. Arch Otolaryngol Head Neck Surg 1997;123:578-83.

15. Troell RJ, Powell NB, Riley RW, Li KK. Evaluation of a new procedure for nasal alar rim and valve collapse: nasal alar rim reconstruction. Otolaryngol Head Neck Surg 2000;122:204-11.

16. Park SS. The flaring suture to augment the repair of the dysfunctional nasal valve. Plast Reconstr Surg 1998;101:1120-2.

17. Tardy ME Jr, Garner ET. Inspiratory nasal obstruction secondary to alar and nasal valve collapse: technique for repair using autogenous cartilage. Oper Tech Otolaryngol-Head Neck Surg 1990;1:215-7.

18. Gunter JP, Friedman RM. Lateral crural strut graft: technique and clinical applications in rhinoplasty. Plast Reconstr Surg 1997;99:943-52; discussion 953-5.

19. Toriumi DM. Surgical correction of the aging nose. Facial Plast Surg 1996;12:205-14.

20. Toriumi DM. Management of the middle nasal vault in rhinoplasty. Oper Tech Plast Reconstr Surg 1995;2:16-30.

21. Becker DG, Becker SS. Treatment of nasal obstruction from nasal valve collapse with alar batten grafts. J Long Term Eff Med Implants 2003;13:259-69.

22. Byrd DR, Otley CC, Nguyen TH. Alar batten cartilage grafting in nasal reconstruction: functional and cosmetic results. J Am Acad Dermatol 2000;43(5 Pt 1):833-6. 